\title{
o prazer do suicídio como performance do sujeito em Barthes
}

(...) je ne suis pas contradictoire, je suis dispersé. (BARTHES, 2002d, p.717)

Rodrigo Ielpo'

RESUMO: Em seu Roland Barthes par Roland Barthes, o crítico exorta seu leitor a considerar o que será lido como "dito por um personagem de romance". Espalhando os signos desse deslocamento ao longo de todo o livro, Barthes evoca novamente a relação entre escritura e desaparecimento do sujeito, desenvolvida anos antes em seu "La mort de l'auteur". 0 que este artigo pretende explorar é de que modo, ao acusar a fissura como posição ontológica do sujeito, Barthes radicaliza a noção de um "eu disperso" para chegar à formulação de um eu como performance.

PALAVRAS-CHAVE: Barthes; Performance; Máscara; Morte do autor.

\section{The suicide pleasure as a performance of the subject in Barthes}

ABSTRACT: In Roland Barthes by Roland Barthes, the critic urges his reader to consider what will be read "as if spoken by a character in a novel". Spreading the signs of this displacement throughout the book, Barthes evokes the relation between writing and the disappearance of the subject, developed years ago in "The death of the author". This article has the intent to explore how, in accusing the fissure of the subject as his ontological position, Barthes radicalizes the notion of a dispersed self in order to think the self as a performance.

KEYWORDS: Barthes; Performance; Mask; The death of the author.

\section{Encenações do distanciamento: 0 autor como máscara}

Em seu Roland Barthes por Roland Barthes, Barthes exorta seu leitor a considerar 0 que será lido como "dito por um personagem de romance" (BARTHES, 2002d, p. 577)2. Espalhando os signos desse deslocamento ao longo de todo o livro, o crítico evoca novamente a relação entre escritura e desaparecimento do sujeito, desenvolvida anos antes em A morte do autor. 0 que esta comunicação pretende explorar é de que modo, ao acusar a fissura como posição ontológica do sujeito, Barthes radicaliza a noção de um "eu disperso" para chegar à formulação de um eu como performance. Neste jogo de cena em que 0 romance termina por dar lugar ao teatro, a escritura operaria como gesto essencial, fazendo do suicídio do autor o processo de encenação das máscaras necessárias às figurações de um sujeito. 0 que está em jogo são as marcas de uma mise en scène que permitirá a Barthes reproduzir ao longo do livro o que Christophe Bident chamará de gestus, indicando através deste termo a "teatralidade da escritura" (BIDENT, 2012) desenvolvida pelo autor. Essa teatralidade pode ser pensada como o dispositivo de figuração que permite a Barthes colocar-se em cena no mesmo momento em que denuncia a distância irredutível em relação a si próprio.

Em um dos momentos em que assume a primeira pessoa do singular em seu Roland Barthes, Barthes fala das virtudes da atopia em relação à utopia: "Fichado: estou fichado, marcado em um lugar (intelectual), em uma residência de casta (se não de classe). Contra 0 quê, uma só doutrina: a da atopia (do habitáculo em deriva)." (BARTHES, 2002d, p. 629) 0 gestus barthesiano permite ao autor encenar a performance dessa deriva, construindo seu constante desaparecimento por meio da multiplicação das máscaras com que procura se dar a ver - não somente a seu leitor como a si mesmo. Colocando como epígrafe de sua performance a necessidade de pensarmos em sua enunciação como sendo a de um

\footnotetext{
${ }^{1}$ É professor de Literatura Francesa da Universidade Federal do Rio de Janeiro (UFRJ). E-mail para contato: rodrigoielpo@gmail.com.

${ }^{2}$ Todos os textos que aparecem em francês no original foram traduzidos por mim.
} 
personagem de romance, Barthes nos remete a um comentário feito em 0 grau zero da escrita. Trata-se dos signos romanescos que, segundo o escritor "não são senão o gesto fatal através do qual o escritor indica a máscara que está usando" (BARTHES, 2002a, p. 195). No livro de que tratamos aqui, essas máscaras, Barthes as expõem,sobretudo,por meio de dois dispositivos: o primeiro diria respeito à construção de um repertório de imagens, construídas sob a forma de fragmentos, que apontariam para o que ele não cessa de nomear como sendo da ordem do imaginário. Conceito de inflexão lacaniana e formando uma espécie de tríade com o simbólico e o real, o imaginário implicaria a impossibilidade assumida por Barthes de dizer a si mesmo sem a mediação do olhar do outro, vendo-se como o isto para o qual a imagem especular o envia ${ }^{3}$. Aqui funcionaria o que Domique Rabaté chamará de "estratégia do parêntese (que impõe a distância) e das aspas" (RABATÉ, 2006, p. 214). Esta estratégia implicaria, como sugere Rabaté citando 0 fragmento de Barthes sobre 0 imaginário, um posicionamento do leitor que o observa, facilitador, ele também, dessa deriva em que o escrito não se fecha nunca: "jamais fechar o parêntese é exatamente: derivar". E nessa relação entre ver e ser visto é que se abriria a fratura que permite a Barthes fazer uso de um segundo dispositivo - condicionador do primeiro -, próprio ao teatro e que, como ele mesmo afirma, viria das reflexões teóricas de Bertolt Brecht. Trata-se da técnica do distanciamento ou, na acepção de Walter Benjamin em seus estudos sobre Brecht, da interrupção (BENJAMIN, 2003).

Em seu Pequeno organon para o teatro, o dramaturgo alemão explica o que seria 0 "efeito de distanciamento", prática integrante, como afirmado no prólogo a esse mesmo texto, de uma "estética retirada de uma maneira particular de fazer teatro" (BRECHT, 2008, p.9). Para Brecht, "uma reprodução que distancia é uma reprodução que, certamente, permite reconhecer o objeto, mas que ao mesmo tempo o faz parecer estrangeiro" (BENJAMIN, 2003, p.40). Ora, como Barthes nos diz no fragmento Moi, je, em seu Roland Barthes,ele fala de si "como 0 ator brechtiano, que deve distanciar seu personagem: 'mostrá-lo', não encarná-lo, e dar à sua dicção como que pequenos golpes cujo efeito é o de descolar o pronome de seu nome, a imagem de seu suporte, o "imaginário de seu espelho", acrescentando logo em seguida: "Brecht recomendava ao autor que pensasse a totalidade de

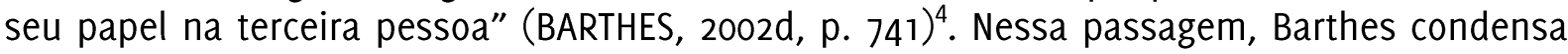
a economia narrativa em torno da qual seu livro se organiza, ligando, em um só gesto, as relações entre escrita autobiográfica e performance. Além disso, ao assumir a passagem do "eu" ao "ele" como técnica teatral proposta por Brecht, Barthes também retoma a problemática concernente à morte do autor, remetendo-nos aos pressupostos blanchotianos segundo os quais a literatura começaria ela mesma nesse movimento. Aliás, no mesmo trecho citado acima, pouco antes da referência a Brecht, Barthes havia afirmado: "falar de si dizendo 'ele' pode querer dizer: falo de mim como se estivesse um pouco morto (...)". (BARTHES, 2002d, p. 741)

Passar do "eu" ao "ele" significaria, assim, assumir os mecanismos de despersonalização cujo princípio Barthes já havia abordado em seu texto célebre, revelandoo como o gesto próprio à escritura. Porém, entre a morte do autor e um "como se" que fabula seu estado um "pouco morto", abre-se o espaço de uma encenação do sujeito, ou, o que parece mais apropriado, do sujeito como encenação. Mas é em outro texto que esse

\footnotetext{
${ }^{3} 0$ livro de Barthes se inicia com uma foto fora de foco de sua mãe caminhando. Algumas páginas depois, após a exposição de diversas outras fotos, o leitor se depara com a imagem refletida de sua mãe segurando 0 pequeno Barthes no colo e mirando-se no espelho como a indicar ao recém-nascido sua própria imagem. Foto perfeita para colocar em cena o discurso do autor e para a qual Barthes escreve a seguinte legenda: "0 estado do espelho: você é isto". In: BARTHES, Roland. "Roland Barthes par Roland Barthes". In: Euvres completes IV. Paris: Éditions du Seuil, 2002.

${ }^{4}$ Esse trecho retoma o comentário feito anos antes por Barthes em seu artigo "La révolutionbrechtienne", implicando dessa vez o espectador: "(...) o público só deve engajar-se em parte no espetáculo, de modo a "conhecer" o que lhe é mostrado, ao invés de se submeter a ele; que o ator deve dar à luz a essa consciência denunciando seu papel, não o encarnando (...)."In: Euvres complètesll. Paris: Éditions du Seuil, 2002, p. 314.
} 
procedimento ganha seus contornos mais nítidos. Em "0 rosto escrito", texto do livro 0 império dos signos, de 1970, Barthes descreve o rosto do ator japonês a partir da relação deste com o uso da máscara, tal como esta se apresenta nos teatros Nô, Kabouki e Bunraku. Barthes destaca nessas máscaras, as quais ele vê como páginas em branco, sua função de apagamento dos traços dos rostos sobre os quais se aplica. Contrapondo-as à maquiagem dos palhaços ocidentais, a qual visaria os mecanismos da caricatura, a máscara do teatro japonês leva "o rosto à extensão vazia de um tecido fosco (...). A face é somente: a coisa a ser escrita (...)" (BARTHES, 2002C, p. 418-419). A parte final dessa citação carrega a ambiguidade que marca a relação entre morte e existência própria ao autor barthesiano tal como desenvolvido em Roland Barthes: a máscara, "coisa a ser escrita", surge como suporte das futuras inscrições e a inscrição mesma, apontando para a escritura como o processo de subjetivação em que apagar-se não é senão encenar o rito de passagem através do qual novas máscaras poderão surgir.

\section{Texto e imagem: jogos especulares da cena}

Retomemos a aproximação com o teatro de Brecht, referência frequente em diferentes momentos de sua obra. É ela que permitirá a Barthes explorar ao máximo um tensionamento entre o signo e o sinal, repensando o regime do visível em que tudo se dá a ver, inclusive o próprio sujeito. No fragmento "Teatro" de Roland Barthes, encontramos a declaração que encena 0 alcance desse procedimento na construção textual do autor: "Na encruzilhada de toda obra, talvez o Teatro: não há nenhum de seus textos, de fato, que não trate de certo teatro (...)". Nesse comentário, o que está em questão é justamente esse regime de visibilidade, pois, como podemos ler em sua continuação, "o espetáculo é a categoria universal sob as espécies da qual o mundo é visto" (BARTHES, 2002d, p. 749). Como podemos depreender de seu texto, pensar esse regime do espetáculo é pensar naquilo que ele chamará de uma sinalética em oposição a uma semiologia. Para aquela, torna-se necessário pensar não no sentido, mas nos mecanismos de significação em que afeto e signo, emoção e teatro expositivo, não podem mais se separar. No caso do sujeito, o que importa não é a interioridade ideal de uma unidade a ser descoberta, mas a operação dos códigos através dos quais este se expõe em suas diferentes montagens, como aparece no "jogo filosófico" proposto por Barthes. Neste,

\footnotetext{
o mundo é visto apenas como um tecido, um texto desenrolando a revolução das linguagens, e no qual o sujeito, disperso, inconstituído, só pode se apreender às custas de um imaginário, a escolha (política, ética) dessa aparência de sujeito não tem nenhum valor de fundamento: essa escolha não é importante; qualquer que seja o modo, pomposo ou violento, através do qual a declaremos, ela não é senão uma inclinação (...). (BARTHES, 2002d, p. 731)
}

No espetáculo do teatro barthesiano em que o sujeito aparece, o que está em jogo são os mecanismos em que a oposição ser/ parecer já não faz o menor sentido, devendo mesmo ser denunciada como ilusória. Numa linguagem cênica isso equivaleria a dizer que não mais seria possível uma distinção entre bastidor e cena de exposição, representando o palco o espaço vazio em que a materialidade dos códigos viria a construir seus sentidos nos jogos de significação.

É nessa via, inclusive, que devemos pensar a relação entre texto e fotografia operada pelo livro de Barthes. As fotos ali presentes teriam uma dupla função: indicar o cenário da mise en scène em que 0 ator/escritor se dá a ver e, no caso daquelas em que o próprio autor aparece, executar uma espécie de desdobramento do "Eu", levando a um processo de unheimlich em que o sujeito não pode se ver senão como estrangeiro a si. Sendo assim, a exposição dessas imagens torna-se também parte do mesmo gesto teatral que marca essa passagem em que o rosto torna-se máscara, aparecendo como signo e não mais como natureza. É $o$ artifício do distanciamento em que a identidade se vê dispersada por um jogo de cena especular, sem que o reflexo tenha um ponto fixo de origem. Como explica Barthes 
em "As tarefas da crítica Brechtiana", "0 papel moral de Brecht é o de inserir vivamente uma pergunta no meio de uma evidência (...)". (BARTHES, 2002b, p. 347)

Isso significa que ao invés de representar um centro gravitacional para o qual todo sentido da obra seria atraído, a confrontação entre a imagem do autor e sua escrita constrói um autorretrato múltiplo, indicando o que Louis Marin chamará de autóptico: "um retrato que só se pintaria ao dobrar-se incessantemente sobre si, ao suspender, descrever e criticar os procedimentos de sua própria figuração, esquivando-se, assim, incessantemente, da atribuição desse "Eu" que agora escreve; que aqui se inscreve" (MARIN, 1999, p. 7). Contrapondo-se ao sujeito clássico, o qual veria sua contradição baseada em pares opositivos desfazer-se sob a tutela reconciliadora da unidade Homem - seu sentido -, 0 sujeito não é afirmado por Barthes como dividido "para reconhecer suas contradições simples, suas duplas postulações, etc: o que é visado é uma difração, um espalhamento em cujo lance não resta mais nem núcleo principal, nem estrutura de sentido (...)" (BARTHES, 2002d, p. 749). Ou seja, as relações entre retrato e texto funcionam como um dispositivo próprio a esse "espalhamento" do sujeito, e não à sua reconciliação.

Pode-se dizer que essa posição ética é alçada a gesto político como intervenção por meio da publicação endereçada à circulação social, pois cabe ao próprio público espectador/leitor dar continuidade ao tensionamento indicado, impossibilitando sua estabilização, como vimos há pouco. Como bem observam Jean-Luc Nancy e Frederico Ferrari em Iconografia do autor,

0 retrato do autor pode ser considerado como bem sucedido quando ele permite que 0 gesto não se fixe, quando ele o deixa libertar-se do achatamento claustrofóbico da imagem e encontrar o espaço necessário para se mover, fazendo vir à superfície alguma coisa que é o indício de outra coisa... (FERRARI at NANCY, 2005, p.34)

Essa "outra coisa", porém, longe de remeter a um possível "escondido", não é senão o traço dessa impossibilidade de fixação do corpo que se dá a ver entre imagem e escrita, pois, insistem os autores, "em sua indecidibilidade, a figura do autor descreve a trajetória de um corpo de escritura submetido às leis do princípio de indeterminação do sentido: mais eu avanço no sentido do texto, mais a evidência da figura do autor me escapa, e vice-versa" (FERRARI \& NANCY, 2005, p.29). Na lógica teatral de Barthes, o corpo, desfeito como origem, inscreve-se radicalmente, como toda imagem, "no movimento infinito dos discursos" (BARTHES, 2002d, p.713) constituintes da logosfera, destituindo todo o princípio de autenticidade ligado à noção de revelação, a qual sustentaria a literatura de "Confissão". Inscrito na trama discursiva, o sujeito não pode ser destacado desta sob o álibi de um centro estável à espera de ser revelado. É o que, paradoxalmente, leva Barthes a confessar: "o que escrevo de mim não é jamais a última palavra: quanto mais sou 'sincero', mais sou interpretável, sob os olhos de outras instâncias que não a dos antigos autores, que acreditavam submeter-se apenas a uma só lei: a autenticidade." (BARTHES, 2002d, p. 696)5 História, Ideologia, Inconsciente: são estas as outras instâncias citadas por Barthes que, pouco importando os componentes desse grupo seleto, crê nesse devir especular do sentido sem nenhuma escatologia que pudesse fixá-lo em uma revelação final.

\section{A máscara mortuária: figurações do autor}

Denunciar não a máscara, mas as máscaras que colocam em cena o imaginário, sem que, como ele nos diz, haja "alguém por trás" (BARTHES, 2002d, p. 695). Assim fazendo, Barthes pretende operar um deslocamento da representação para a figuração, como explicitado por uma passagem de 0 prazer do texto. Afirmando a diferença entre os dois

\footnotetext{
${ }^{5}$ Em fragmento anterior a este, Barthes já havia anunciado: "Não procuro colocar minha expressão presente a serviço de minha verdade anterior (em regime clássico, este esforço seria santificado sob o nome de autenticidade)." In: BARTHES, Roland. "Roland Barthes par Roland Barthes". Euvres complètes IV. Paris: Éditions du Seuil, 2002, p.637
} 
mecanismos, Barthes distingue a via escatológica que na representação construiria um sentido para a vida, inscrevendo-a em um destino, daquela aberta pela figuração. Esta, segundo o autor, "seria o modo de aparição do corpo erótico (...) no perfil do texto", explicando que no regime figurativo "o autor pode aparecer em seu texto (Genet, Proust), mas não sob os modos da biografia direta (...)" (BARTHES, 2002d, p. 253-254). Logo, podemos pensar na disposição das fotos no início do livro como a construção cenográfica própria ao regime figurativo, pois mais do que insistir na construção imagética de uma identidade, as fotografias, em conjunção com os textos que as acompanham, não cessam de operar o dispositivo de distanciamento do teatro épico de Brecht, como já vimos. Assim, da figura inicial da mãe, mediadora do imaginário, à foto que abre a série de fragmentos e onde podemos ver o cliché do Barthes intelectual, contemporâneo à escrita de seu próprio texto, uma sentença não para de reverberar: "Mas eu jamais me pareci com isto!" (BARTHES, 2002d, p. 616)

Ao invés de aproximar o escrito da imagem, aproximando o espectador/leitor de um centro identitário cujo sentido seria assim reforçado, a acumulação desses diferentes médiuns repete o movimento de distanciamento que trabalha a figuração do próprio sujeito. Novamente, a teatralidade intervém como denúncia dos códigos, construindo um cenário introdutório que expõe em toda a sua evidência a realidade de signo daquilo que é dado a ver: eis a sinalética comentada anteriormente. Como nos explica Bident, "[a] imagem em Barthes já é sempre um signo, o que a desloca de um estatuto analógico para um estatuto diacrítico (...)" (BIDENT, 2012, p.38).Brecht, sempre ele, é quem serve de guia para esse teatro.

Em "Literatura e significação", podemos ler a seguinte passagem:

\begin{abstract}
Brecht pressentiu a variedade e a relatividade dos sistemas semânticos: 0 signo teatral não é uma coisa óbvia; aquilo que chamamos de natural num ator ou de verdade numa atuação, é apenas uma linguagem entre outras (uma linguagem realiza sua função, que é de comunicar, por sua validade, não por sua verdade), e essa linguagem é tributária de um certo quadro mental, isto é, de uma certa história, de modo que mudar os signos (e não somente o que eles dizem), é dar à natureza uma nova distribuição (empresa que define precisamente a arte), e fundar essa distribuição não sobre leis "naturais", mas muito pelo contrário sobre a liberdade que os homens têm de fazer significar as coisas. (BARTHES, 2002b, p. 510-511)
\end{abstract}

Dessa forma, como procurei demonstrar, colocar o "eu" em cena é sempre encenar um 'eu', expondo os processos de significação presentes em cada exercício cênico. E encenar, segundo a definição encontrada em Roland Barthes, seria "escalonar suportes, dispersar papéis, estabelecer níveis e, no limite: fazer da ribalta uma barra incerta" (BARTHES, 2002d, p.681). Nessa atuação sem garantias é que se dá o jogo pronominal em que as aparições do autor acontecem sobretudo na figura de um 'ele'. E "dizendo de alguém 'ele', conta Barthes, sempre me vem à mente uma espécie de assassinato pela linguagem, cujo palco inteiro, às vezes suntuoso, cerimonial, é o falatório" (BARTHES, 2002d, p.741).Mas no regime da figuração em que a sinalética reina, 0 assassinato em questão se dá a ver como performance, como estado de passagem entre múltiplas máscaras que aparecem e somem em meio ao falatório indicado. Se fosse possível retê-las no tempo, justapondo-as em um único exemplar, elas apontariam para a idealidade do rosto do autor barthesiano: uma máscara mortuária que revelasse a si mesma como código supremo do desejo de morte no ritual da escritura. Mas, se como diz Barthes, "o gozo não é aquilo que responde ao desejo (o satisfaz), mas aquilo que o surpreende, o excede, o desorienta, o desencaminha" (BARTHES, 2002d, p. 688), esse rosto ideal, ao mirar-se no espelho, reencenaria sua própria morte em piscadelas bem vivas àquele que o olha : "Tu és isto". 


\section{REFERÊNCIAS}

BARTHES, Roland. Euvres complètes IV. Paris: Éditions du Seuil, 2002d. . Euvres complètes III. Paris: Éditions du Seuil, 2002c. . Euvres complètes II. Paris: Éditions du Seuil, 2002b. . Euvres complètes I. Paris: Éditions du Seuil, 2002a.

BENJAMIN, Walter. Essais sur Brecht. Trad. Philippe Ivernel. Paris: La Fabrique, 2003. BERTOLT, Brecht, Petit organon pour le théâtre, trad. Jean Tailleur, Paris, L'Arche, 2008. BIDENT, Christophe. Le geste théâtral de Roland Barthes. Paris: Hermann, 2012. FERRARI, Frederico At NANCY, Jean-Luc. Iconografia de l'auteur. Paris: Galilée, 2005. MARIN, Louis. "Roland Barthes par Roland Barthes ou l'autobiographie au neutre". In: Critique, nć 423-424. Paris: Minuit, 1982, p.734-743.

RABATÉ, Dominique. "Le singulier pluriel: Roland Barthes". In: Le chaudron fêlé. Paris: José Corti, 2006, p.199-221 